associated with treatment response and disease progression. However, it is not known whether joint size is associated with specific pathotypes.

Objectives: To analyse histopathological features of synovial biopsies from joints of different sizes and establish the relationship with clinical outcomes in patients with early RA.

Methods: 167 patients with early ( $<1$ year) treatment-naïve RA, fulfilling the 2010 RA criteria and recruited at Barts Health NHS Trust, underwent US-guided synovial biopsy of the most inflamed joint, either large (knee), medium (e.g. wrist, ankle, elbow) or small (MCPs, MTPs), before starting treatment with csDMARDS with a treat to target approach. Upon SQ scoring (0-4) of immune cell infiltration, tissues were classified into lympho-myeloid, diffuse-myeloid and pauci-immune pathotypes. Synovial samples from 111 patients underwent RNA-seq.

Results: The majority of synovial biopsies were performed on medium and small joints $(60.6 \%$ and $19.4 \%)$ as compared to $21.3 \%$ in large joints (Table 1). At baseline, patients who underwent large joint biopsy showed significantly higher levels of inflammation (CRP 27.9 \pm 32.4 large, 20.7 \pm 26.9 medium, $10.4 \pm 9.8$ small, $p=0.007)$ and higher $\mathrm{HAQ}(1.8 \pm 0.7$ large, $1.4 \pm$ 0.8 medium, $1.2 \pm 0.9$ small, $p=0.012$ ), with no differences in DAS28. Significantly higher inflammatory scores and higher proportion of lympho-myeloid pathotype were observed in large joints (Table 1 and Figure 1). 6 months after treat-to-target treatment with csDMARDs, large joints patients had significantly higher $\mathrm{HAQ}$ and lower response (RR for low disease activity in large vs medium joints $0.5,95 \% \mathrm{Cl} 0.2-0.9, \mathrm{p}=0.03$ ). Finally, differentially expressed genes by RNA-seq showed segregation according to joint size (Figure 2), with upregulation of genes of the Homeobox transcription factors family in large joints.

Table 1. EULAR 2010 RA $(n=167)$

\begin{tabular}{|c|c|c|c|c|c|}
\hline & & $\begin{array}{c}\text { Large joints\# } \\
33(19.4 \%)\end{array}$ & $\begin{array}{c}\text { Medium joints\# } \\
100(60.6 \%)\end{array}$ & $\begin{array}{c}\text { Small Joints\# } \\
34(20 \%)\end{array}$ & $P^{*}$ \\
\hline \multicolumn{6}{|l|}{ Clinical features } \\
\hline ESR $\mathrm{mm} / \mathrm{h}$, mean (SD) & & $48.2(31.5)$ & $39.6(30.8)$ & $29.2(17.3)$ & ns \\
\hline CRP mg/L, mean (SD) & & $27.9(32.4)$ & $20.7(26.9)$ & $10.4(9.8)$ & 0.007 \\
\hline DAS28, mean (SD) & & $6(1.2)$ & $5.7(1.4)$ & $5.7(1.5)$ & ns \\
\hline HAQ, mean (SD) & & $1.8(0.7)$ & $1.4(0.8)$ & $1.2(0.9)$ & 0.012 \\
\hline ACPA-positive, $\%$ & & $70.9 \%$ & $77.3 \%$ & $83.9 \%$ & ns \\
\hline RF-positive, \% & & $71.9 \%$ & $74.2 \%$ & $80.6 \%$ & ns \\
\hline \multicolumn{6}{|l|}{ Histology } \\
\hline $\begin{array}{l}\text { Inflammatory score, } \\
\text { median IQR) }\end{array}$ & & $5(3)$ & $4(4)$ & $2(2.75)$ & $<0.001$ \\
\hline \multirow{4}{*}{ Pathotype, \% } & Ungraded & $6.1 \%$ & $7.8 \%$ & $2.9 \%$ & 0.014 \\
\hline & Fibroid & $6.1 \%$ & $24.3 \%$ & $32.3 \%$ & \\
\hline & Myeloid & $30.3 \%$ & $28.1 \%$ & $47.1 \%$ & \\
\hline & $\begin{array}{l}\text { Lympho- } \\
\text { myeloid }\end{array}$ & $57.6 \%$ & $39.8 \%$ & $17.6 \%$ & \\
\hline
\end{tabular}

Clinical outcomes at 6 months

\begin{tabular}{lcccc}
\hline DAS28 6m, mean (SD) & $4.2(1.8)$ & $3.4(1.9)$ & $3.7(1.5)$ & $\mathrm{ns}$ \\
HAQ $6 \mathrm{~m}$, mean (SD) & $1.2(0.8)$ & $0.8(0.8)$ & $0.8(0.8)$ & 0.012 \\
DAS28 6m <3.2, \% & $23.3 \%$ & $48.8 \%$ & $37.9 \%$ & 0.04
\end{tabular}

\#Large joints: knees; Medium joints: wrists, ankle, elbows; Small joints: MCPs, MTPs, PIPs; * Chi-squared or Kruskal-Wallis as appropriate;

Conclusion: Synovial biopsy of large joints as the most inflamed joints at disease presentation identified patients with early RA with specific histopathological features and clinical outcomes. Together with clustering of differentially expressed genes according to joint size, this suggests that the involvement of different joint compartments in early RA contributes to disease heterogeneity with potential physiopathological and clinical implications.

References:

[1] Humby et al Ann Rheum Dis. 2019 Jun;78(6):761-772

[2] Lewis et al Cell Rep. 2019 Aug 27;28(9):2455-2470.e5

[3] Linn-Rasker SP et al Ann Rheum Dis. 2007 May;66(5):646-50

Acknowledgments: PEAC http://www.peac-mrc.mds.qmul.ac.uk MRC grant 36661 \& ARUK Grant 20022

F. Rivellese NIHR Fellowship TRF-2018-11-ST2-002
Figure 1
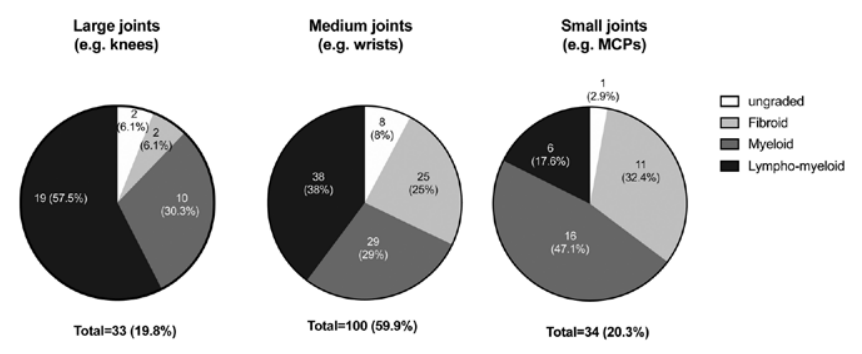

Figure 2

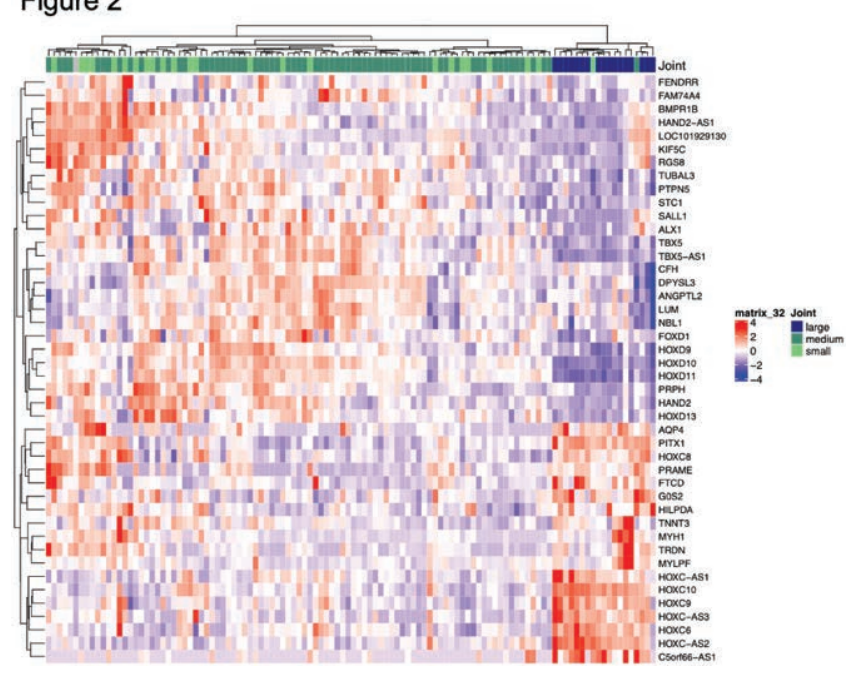

Disclosure of Interests: None declared

DOI: 10.1136/annrheumdis-2020-eular.2475

\section{OP0218 \\ CENTRAL NERVOUS SYSTEM PAIN RESPONSE AND COMPONENTS OF DISEASE ACTIVITY IN RA PATIENTS AFTER TREATMENT WITH CERTOLIZUMAB OR PLACEBO: A POST-HOC ANALYSIS FROM THE PRECEPRA TRIAL}

H. Schenker ${ }^{1}$, J. Rech ${ }^{1}$, K. Tascilar ${ }^{1}$, M. Hagen ${ }^{1}$, V. Schönau ${ }^{1}$, M. Sergeeva ${ }^{2}$, M. Selvakumar', L. Konerth ${ }^{2}$, J. Prade ${ }^{2}$, S. Strobelt ${ }^{2}$, L. Valor ${ }^{1}$, A. Hueber ${ }^{3}$, D. Simon ${ }^{1}$, A. Kleyer ${ }^{1}$, F. Behrens ${ }^{4}$, J. A. P. Da Silva ${ }^{5}$, C. Baerwald ${ }^{6}$, S. Finzel ${ }^{7}$, R. Voll ${ }^{7}$, E. Feist ${ }^{8,9}$, A. Doerfler ${ }^{10}$, N. Damjanov ${ }^{11}$, A. Hess ${ }^{2}$, G. Schett ${ }^{1}{ }^{1}$ FriedrichAlexander University (FAU) Erlangen-Nürnberg and Universitätsklinikum Erlangen, Department of Internal Medicine 3 - Rheumatology and Immunology, Erlangen, Germany; ${ }^{2} F A U$ Erlangen-Nürnberg, Institute for Experimental Pharmacology, Erlangen, Germany; ${ }^{3}$ Sozialstiftung Bamberg, Section Rheumatology, Bamberg, Germany; ${ }^{4}$ Goethe University Frankfurt, Rheumatology and Fraunhofer TMP, Frankfurt am Main, Germany; ${ }^{5}$ Hospitais da Universidade (SRHUC), Department, Coimbra, Portugal; ${ }^{6}$ Universität Leipzig, Medizinische Klinik III - Bereich Rheumatologie, Leipzig, Germany; ${ }^{7}$ Universitätsklinikum Freiburg, Klinik für Rheumatologie und Klinische Immunologie, Freiburg, Germany; ${ }^{8}$ Klinik für Rheumatologie der Helios Fachklinik, Vogelsang-Gommern, Germany; ${ }^{9}$ Charité - Universitätsmedizin Berlin, Dpt. of Rheumatology and Clinical Immunology, Berlin, Germany; ${ }^{10}$ Friedrich-Alexander University (FAU) Erlangen-Nürnberg and Universitätsklinikum Erlangen, Abteilung für Neuroradiologie, Erlangen, Germany; ${ }^{11}$ Belgrade University School of Medicine, Institute of Rheumatology, Belgrade, Serbia

Background: We have previously observed in RA patients that central nervous system (CNS) response to compression of a painful joint, measured using functional MRI (fMRI) of the brain as the number of blood oxygen level dependent (BOLD) signal positive voxels, is rapidly ameliorated, much earlier than any clinical response with anti-TNF treatment and a high baseline CNS pain response could predict better response to certolizumab pegol (CZP) treatment. Pre-CePRA was designed and conducted to test this effect in a randomized, placebo controlled trial of CZP and showed an incremental linear trend of DAS28 low disease activity (LDA) across study groups treated with placebo, and two CZP arms stratified as low or high pre-treatment CNS pain response. 
Objectives: To explore and describe pre-treatment CNS pain response associations with post treatment course of RA disease activity components and patient-physician discrepancy in global disease assessment.

Methods: Patients fulfilling the 2010 ACR/EULAR classification criteria with moderate-severe disease activity (DAS-28>3.2) under stable DMARD treatment were recruited. Patients underwent an fMRI scan, stratified by a whole-brain BOLD positive voxel count threshold of 700 units and randomized to treatment with CZP or placebo in a 2:1 ratio. We descriptively assessed components of RA disease activity (Table $1+2$ ). We summarized the mean results and $95 \%$ confidence intervals of these measurements at study timepoints and compared the 3 study groups at week 12 using one-way ANOVA and post-hoc Tukey tests. Results: 156 eligible patients were screened and 139 (99 females, $71 \%$ ) patients with moderate-high disease activity were randomized. ANOVA and pairwise comparisons showed that PGA-VAS improvement was larger in the CZP-H group whereas more similar to that in placebo in the CZP-L group. PhysGA-VAS however was similarly reduced in both CZP groups. Patients in the CZP-L group constantly rated their pain numerically higher than physicians whereas in the CZP-H group an initially higher discrepancy numerically reduced over time.

Conclusion: These results suggest that improved patient global disease activity assessment could be the main driver of improved DAS-28 LDA rates with CZP treatment in patients with a high CNS pain response. Our findings indicate a potential role of fMRI imaging of the brain to further understand disease activity perception in RA patients.

Disclosure of Interests: Hannah Schenker: None declared, Jürgen Rech Consultant of: BMS, Celgene, Novartis, Roche, Chugai, Speakers bureau: AbbVie, Biogen, BMS, Celgene, MSD, Novartis, Roche, Chugai, Pfizer, Lilly, Koray Tascilar: None declared, Melanie Hagen: None declared, Verena Schönau: None declared, Marina Sergeeva: None declared, Mageshwar Selvakumar: None declared, Laura Konerth: None declared, Jutta Prade: None declared, Sandra Strobelt: None declared, Larissa Valor: None declared, Axel Hueber Grant/ research support from: Novartis, Lilly, Pfizer, EIT Health, EU-IMI, DFG, Universität Erlangen (EFI), Consultant of: Abbvie, BMS, Celgene, Gilead, GSK, Lilly, Novartis, Speakers bureau: GSK, Lilly, Novartis, David Simon Grant/ research support from: Else Kröner-Memorial Scholarship, Novartis, Consultant of: Novartis, Lilly, Arnd Kleyer Consultant of: Lilly, Gilead, Novartis,Abbvie, Speakers bureau: Novartis, Lilly, Frank Behrens Grant/research support from:

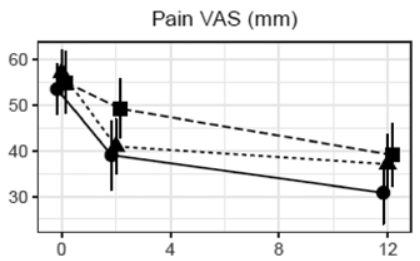

Physician global VAS, mm

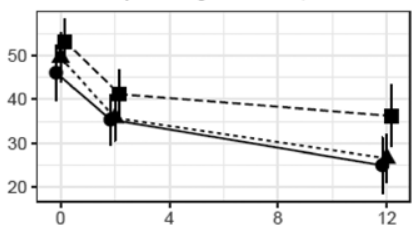

Swollen joint count* *

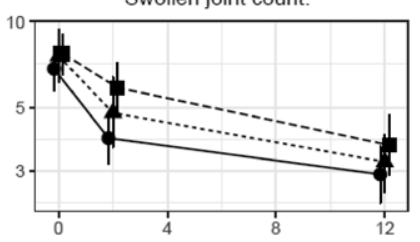

$\mathrm{ESR}, \mathrm{mm} / \mathrm{h}^{*}$

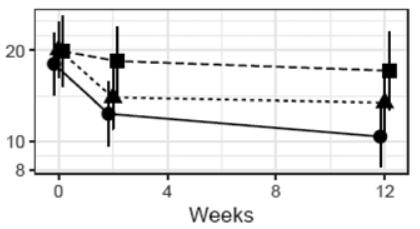

Study group - Certolizumab-High

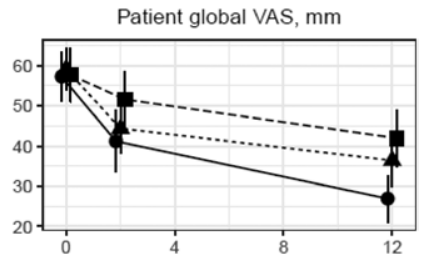

PGA-Phys.GA discrepancy, $\mathrm{mm}^{* *}$

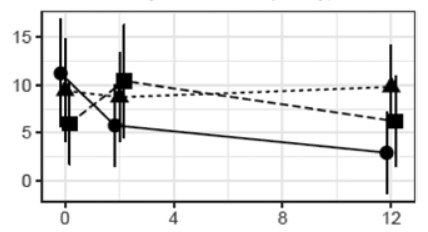

Tender joint count.

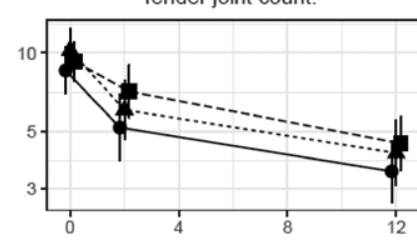

$\mathrm{CRP}, \mathrm{mg} / \mathrm{L}^{*}$

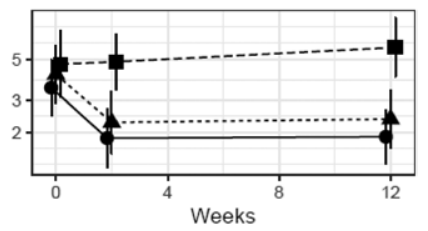

- Certolizumab-Low $\rightarrow$. Placebo

Figure 1. Course of disease activity components through trial timepoints. *indicates log-transformed y axis. ${ }^{* \star}$ Discrepancy equals Patient global minus physician global assessment.
Table 1: Baseline paticnt characteristics.

\begin{tabular}{|c|c|c|c|c|c|}
\hline & & & \multicolumn{3}{|c|}{ Study group } \\
\hline & & & Certolixumab-Iligh & Certolizumab-Low & Placebo \\
\hline $\mathrm{N}$ & & & 43 & 49 & 47 \\
\hline Age & & $\operatorname{Mean}(\mathrm{SD})$ & $54.3(10.8)$ & $56.5(12.2)$ & $52.1(12.0)$ \\
\hline \multirow{2}{*}{ Sex } & female & $n(\%)$ & $34(79.1)$ & $35(71.4)$ & $30(63.8)$ \\
\hline & male & $\mathrm{n}(\%)$ & $9(20.9)$ & $14(28.6)$ & $17(36.2)$ \\
\hline \multirow{2}{*}{ Diescase duration } & & Mean(SD) & $6.0(8.3)$ & $6.4(8.6)$ & $6.2(7.6)$ \\
\hline & & Median(IQR) & $2.0(1.0-9.0)$ & $3.0(1.0-8.0)$ & $3.0(1.0-8.0)$ \\
\hline \multirow{2}{*}{ ACPA } & Negative & $n(\%)$ & $15(34.9)$ & $9(18.4)$ & $10(21.3)$ \\
\hline & Positive & $n(\%)$ & $28(65.1)$ & $40(81.6)$ & $37(78.7)$ \\
\hline \multirow{2}{*}{$\mathrm{RF}$} & Negative & $\mathrm{n}(\%)$ & $12(27.9)$ & $13(26.5)$ & $14(29.8)$ \\
\hline & Positive & $\mathrm{n}(\%)$ & $31(72.1)$ & $36(73.5)$ & $33(70.2)$ \\
\hline Tender joints (28) & & Mean(SD) & $9.3(6.4)$ & $11.3(6.7)$ & $9.9(6.2)$ \\
\hline Swollen joints (28) & & $\operatorname{Mean}(\mathrm{SD})$ & $7.0(4.4)$ & $8.7(6.3)$ & $8.0(4.8)$ \\
\hline Patient global VAS, mn & & $\operatorname{Mean}(\mathrm{SD})$ & $57.2(19.9)$ & $59.1(17.8)$ & $57.6(22.5)$ \\
\hline Physician global VAS, mm & & Mean(SD) & $46.0(20.2)$ & $49.5(19.2)$ & $53.1(16.2)$ \\
\hline Pain VAS & & Mean(SD) & $53.5(18.0)$ & $57.1(17.0)$ & $54.9(22.7)$ \\
\hline ESR & & Mean(SD) & $23.7(19.0)$ & $25.2(17.1)$ & $28.2(23.2)$ \\
\hline CRP & & $\operatorname{Mean}(\mathrm{SD})$ & $6.8(12.7)$ & $7.9(8.7)$ & $11.2(16.5)$ \\
\hline DAS28 & & Mean(SD) & $4.7(1.0)$ & $5.0(1.1)$ & $4.9(1.0)$ \\
\hline
\end{tabular}

\begin{tabular}{|c|c|c|c|c|}
\hline & Comparison & Difference & $96 \% \mathrm{Cl}$ & P value \\
\hline \multirow[t]{3}{*}{ Pain-VAS } & CZP-L-CZP-II & 6.26 & -4.87 to 17.38 & 0.379 \\
\hline & Placebo-CZP-II & 8.28 & -2.85 to 19.41 & 0.186 \\
\hline & Placebo-CZP-L & 2.02 & -8.85 to 12.89 & 0.899 \\
\hline \multirow[t]{3}{*}{ PGA-VAS } & CZP-L-CZP-H & 9.49 & -1.23 to 20.20 & 0.094 \\
\hline & Placebo-CZP-H & 14.99 & 4.27 to 25.70 & 0.003 \\
\hline & Placebo-CZP-L & 5.50 & -4.97 to 15.97 & 0.429 \\
\hline \multirow[t]{3}{*}{ PhysGA-VAS } & CZP-L-CZP-H & 1.59 & -8.91 to 12.08 & 0.932 \\
\hline & Placebo-CZP-H & 11.22 & 0.67 to 21.77 & 0.034 \\
\hline & Placebo-CZP-L & 9.64 & -0.54 to 19.81 & 0.068 \\
\hline \multirow{3}{*}{ PGA-PhysGA Discrepancy } & CZP-L-CZP-H & 6.90 & -0.50 to 14.30 & 0.073 \\
\hline & Placebo-CZP-H & 3.30 & -4.14 to 10.74 & 0.546 \\
\hline & Placebo-CZP-L & -3.60 & -10.78 to 3.57 & 0.461 \\
\hline \multirow[t]{3}{*}{ SJC-28 } & CZP-L_CZP-H & 0.47 & -1.26 to 2.19 & 0.796 \\
\hline & Placebo-CZP-H & 1.21 & -0.52 to 2.93 & 0.225 \\
\hline & Placebo-CZP-L & 0.74 & -0.95 to 2.43 & 0.554 \\
\hline \multirow[t]{3}{*}{ TJC-28 } & CZP-L-CZP-HI & 0.16 & -0.28 to 0.61 & 0.664 \\
\hline & Placebo-CZP-H & 0.25 & -0.20 to 0.69 & 0.389 \\
\hline & Placebo-CZP-L & 0.08 & -0.35 to 0.52 & 0.889 \\
\hline \multirow[t]{3}{*}{ ESR } & CZP-L-CZP-H & 6.53 & -2.80 to 15.85 & 0.225 \\
\hline & Placebo-CZP-II & 11.77 & 2.44 to 21.09 & 0.009 \\
\hline & Placebo-CZP-L & 5.24 & 3.87 to 14.35 & 0.363 \\
\hline \multirow[t]{3}{*}{ CRP } & CZP-L-CZP-H & 0.79 & -7.01 to 8.59 & 0.969 \\
\hline & Placebo-CZP-H & 8.24 & 0.48 to 16.00 & 0.035 \\
\hline & Placebo-CZP-L & 7.45 & -0.17 to 15.07 & 0.057 \\
\hline
\end{tabular}

Abbvie, Pfizer, Roche, Chugai, Janssen, Consultant of: Abbvie, Pfizer, Roche, Chugai, UCB, BMS, Celgene, MSD, Novartis, Biotest, Janssen, Genzyme, Lilly; Boehringer; Sandoz, Speakers bureau: Abbvie, Pfizer, Roche, Chugai, UCB BMS, Celgene, MSD, Novartis, Biotest, Janssen, Genzyme, Lilly; Boehringer; Sandoz, José Antonio P. da Silva Grant/research support from: Pfizer, Abbvie, Consultant of: Pfizer, AbbVie, Roche, Lilly, Novartis, Christoph Baerwald Consultant of: CGB received speaker or consulting fees from AbbVie, Paid instructor for: CGB received speaker or consulting fees from AbbVie, Speakers bureau: CGB received speaker or consulting fees from AbbVie, Stephanie Finzel: None declared, Reinhard Voll: None declared, Eugen Feist Consultant of: Novartis, Roche, Sobi, Lilly, Pfizer, Abbvie, BMS, MSD, Sanofi, Speakers bureau: Novartis, Roche, Sobi, Lilly, Pfizer, Abbvie, BMS, MSD, Sanofi, Arnd Doerfler: None declared, Nemanja Damjanov Grant/research support from: from AbbVie, Pfizer and Roche, Consultant of: AbbVie, Gedeon Richter, Merck, Novartis, Pfizer, and Roche, Speakers bureau: AbbVie, Gedeon Richter, Merck, Novartis, Pfizer, and Roche, Andreas Hess: None declared, Georg Schett Speakers bureau: AbbVie, BMS, Celgene, Janssen, Eli Lilly, Novartis, Roche and UCB DOI: 10.1136/annrheumdis-2020-eular.5346

\section{OP0219 \\ MORTALITY OF RHEUMATOID ARTHRITIS PATIENTS, TREATED TO TARGET AT LOW DISEASE ACTIVITY: 17-YEARS FOLLOW-UP OF THE BEST COHORT}

J. M. Maassen ${ }^{1}$, Y. Goekoop-Ruiterman ${ }^{2}$, H. Van Groenendael ${ }^{3}$, W. Lems ${ }^{4}$ P. Kerstens ${ }^{5}$, T. Huizinga ${ }^{1}$, C. Allaart ${ }^{1}{ }^{1}$ Leiden University Medical Center (LUMC), Rheumatology, Leiden, Netherlands; ${ }^{2}$ Haga Ziekenhuis, Rheumatology, Den Haag, Netherlands; ${ }^{3}$ Reumazorg Zuid West Nederland, Roosendaal, Netherlands; ${ }^{4}$ Amsterdam UMC loc. VUmc, Rheumatology, Amsterdam, Netherlands; ${ }^{5}$ Dijklander Ziekenhuis, Rheumatology, Hoorn, Netherlands

Background: Rheumatoid arthritis is known to be associated with increased mortality over the years when compared to the general population. In the BeSt study, 508 patients were treated to target (Disease Activity Score $\leq 2.4$ ) for 10 years between April 2000 and August 2012. At the end of the initial study follow-up, the observed mortality in the BeSt cohort was similar to mortality in the general population. In the current study we evaluated the mortality in the BeSt cohort after 17 years follow-up and compared it to the general Dutch population.

Objectives: Evaluate long-term mortality in the BeSt study cohort.

Methods: In the BeSt study 508 patients diagnosed with early RA were randomized to four initial treatment strategies: 1. Sequential monotherapy; 2. Step-up 